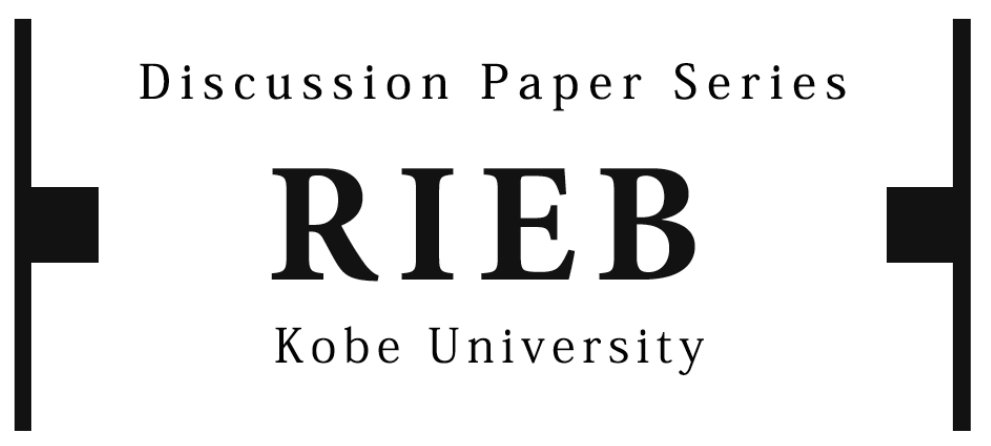

DP2020-18

\title{
Unplanned Purchase of New Products
}

\author{
Ryo KATO
}

Takahiro HOSHINO

May 26, 2020

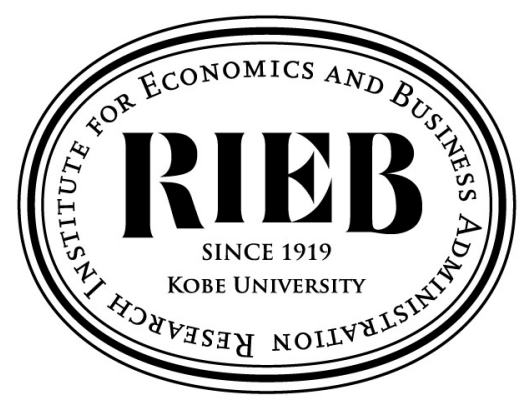

Research Institute for Economics and Business Administration Kobe University 


\title{
Unplanned Purchase of New Products
}

\author{
Ryo Kato \\ Research Institute for Economics and Business Administration, Kobe University, 2-1 \\ Rokkodai-cho, Nada-ku, Kobe, Japan \\ and
}

\section{Takahiro Hoshino}

Department of Economics, Keio University, 2-15-45 Mita, Minato-ku, Tokyo, Japan /

RIKEN Center for Advanced Intelligence Project, 1-4-1 Nihonbashi, Chuo-ku, Tokyo, Japan

\begin{abstract}
Manufacturers are eager to recoup the investment on developing new products by promoting the unplanned first (trial) purchase on the consumer's first sight and by encouraging the succeeding repurchases because they had put in large amount of resources for developing new product. However, studies are yet to investigate the relationship between unplanned purchases and the succeeding repurchase for new product because data on this, including consumers' extensive purchase history and a questionnaire on unplanned buying, are simultaneously unavailable. This study employed a novel "instant research" method to obtain both the purchase history and a questionnaire on impulse buying. Regulatory focus theory, which has recently received considerable attention in psychology and marketing, is helpful in predicting the result. Promotion-focus positively affects unplanned buying of new products as well as customer satisfaction, and leads to an increase in subsequent repeat purchases. The results are consistent with our expectations, indicating that if the first purchase of a new product is unplanned, the succeeding repeat purchases tend to increase compared to a planned trial purchase. We also found that this propensity is more prominent for customers who have higher loyalty to the same or similar category product.
\end{abstract}

Keywords: Unplanned purchase, new product, regulatory focus theory 


\section{Introduction}

Developing new products and product innovations can be large and longlasting sources of margins for innovators (Geroski et al. 1993). They can also help in taking advantage of the competition (Wind and Mahajan 1997). However, developing new products is a risky investment (even though much of the research and development costs are defrayed) as there exists a high degree of uncertainty about whether these products will be accepted in markets. If manufacturers invest in a large number of resources when developing a new product, they are eager to recoup the investment on it by actively causing shoppers' trial purchases and the succeeding repeat purchases. Following the importance of new products to firms, most marketing and management literature has focused on product innovations with adoption and diffusion in markets (Rogers 1995).

Another field of study that has gathered substantial attention is unplanned (or impulse) purchasing. When shoppers browse new products in their shopping path and decide to buy it because of, say, exposure to the commercial stimuli (displays or promotions), they commit to an unplanned purchase. If this purchase is at first sight and if the customer recognizes the new product, the purchase must be unplanned buying. Thus, unplanned purchases and the (first) trial purchase of a new brand are strongly associated.

Simultaneously, manufacturers invest large amounts on promotions for new products before launching them to let potential users recognize and be interested in them beforehand. Advertising is a significantly important marketing strategy to influence customers into trying a new product (Krishnan and Jain 2006). Besides promotions, customers become aware of new products also through in-store displays, websites, or word-of-mouth communication, which can trigger customers' planned purchases. Thus, the trial purchase of new products can be caused in both planned and unplanned manners.

Despite the importance of understanding unplanned purchases of new products for scholars and professionals, academic literature on unplanned purchases has been limited to existing products (Stern 1962; Rook 1987; Inman et al. 2009; Bell et al. 2011; Hui et al. 2013). These prior studies ask shoppers after they shop at a supermarket or 
grocery store if each brand purchased was planned or unplanned. They investigated the factors affecting the probability of making unplanned purchases such as consumer characteristics, product category, or customer activities in the store (Wood 1998; Inman et al. 2009; Bell et al. 2011; Hui et al. 2013). However, the newness and uncertainty of new products lead to a different kind of decision-making process compared to that of existing products, and most research treats innovative products as a different subject of study. Therefore, the results on unplanned purchases of innovative products can be different from those of existing products.

The absence of surveys on unplanned purchases of a new product that employ real purchase data may be attributed to data limitations; researchers cannot find the true first purchase and following repeat purchases for shoppers unless they grasp customers' entire purchase history across all channels, such as supermarkets, grocery stores, drug stores, vending machines, and so on. Surveying simply one retail store is inadequate for understanding the first purchase of a new product, as shoppers may have already sampled that product at other stores or via other channels. Furthermore, their purchase history data must be combined with questionnaires about purchase impulsiveness.

In contrast to prior studies, we use a scanner panel dataset linked with a short questionnaire on unplanned purchases, which enables us to understand the entire purchase history of all survey respondents. Therefore, we can determine if the "real" first trial purchase of a new product is planned or unplanned. Moreover, the data contains respondents' succeeding repeat purchases of the product as well as past purchase history for existing products.

We investigate the relationship between the first unplanned trial purchase and the following repeat purchases of a new product. Wood (1998), Hoch and Loewentein (1991), and Saleh (2012) indicated the consistent result that unplanned buying results in post-purchase regret. However, as a conflicting hypothesis, regulatory focus theory (Higgins 1997, 1998) implies that customers who engaged in unplanned buying are more likely to gain satisfaction. Given the importance of succeeding repeat purchases for long-lasting profit to the innovator and marketing strategies to increase customers' unplanned purchases using in-store stimuli, it is important to investigate the effect of the unplanned trial purchase on the repeat purchases of new products.

In addition, we consider the effects of loyalty (or knowledge) built by an existing 
product. New product knowledge is associated with unplanned purchase behavior (Harmancioglu et al. 2009) and existing products that are similar to new products set similar expectations (Olshavsky and Spreng 1996). We take into account the effect of new product knowledge that consists of a similar existing brand on the unplanned buying behavior of new products using real purchase history. As some brand loyalty or knowledge proxies can be calculated using purchase history data, the implications obtained from the analysis are substantial for managers who are willing to succeed in new product launches.

Based on these motivations and our dataset, we investigate:

1. If the unplanned trial purchase of new products affects the quantity of succeeding repeat purchases

2. How the brand loyalty and knowledge of other related existing products affect the new product trial purchase and succeeding repeat purchase.

\section{Background and hypothesis}

Although it is very important to induce the shopper's intention to new brand unplanned purchases from the perspective of shopper marketing strategies, few studies exist on the unplanned purchase of a new brand (Harmancioglu et al. 2009). Many researchers have taken an interest in the unplanned purchase of an existing brand, but the buying process of new products is different from that of an existing brand (e.g., Hirshman 1980). As noted, we study the effect of trial unplanned purchase of a new product on succeeding repeat purchase. As our prediction mainly depends on regulatory focus theory, first, we introduce the theory itself.

\subsection{Regulatory focus theory}

Regulatory focus theory accounts for the way people employ self-regulation during goal-pursuing (Haws et al. 2010). The theory distinguishes two regulatory orientations, promotion-focus and prevention-focus. The former is more sensitive to opportunities for advancements and more motivated to achievements, while the latter is 
more sensitive to occasions to threats and more motivated in avoiding hazards to reach safety and security. It is recently being studied in the marketing context, especially in the consumer behavior (Chernev 2004; Yeo and Park 2006; Herzenstein et al. 2007; Arnold and Reynolds 2009; Jung and Yoon 2015; Das 2016) because of its explanatory power for various phenomena as shown in many relevant studies.

\subsection{Promotion /prevention-focus, new product, and unplanned purchase}

It is implied that regulatory focus also influences the decision making on new products. Such products are riskier than existing products as shoppers do not know their attributes well and they have many types of risk (perceived risk, functional risk, social risk, economic risk, and physical risk; Ram and Sheth 1989). However, they also attain potential benefits for consumers by fulfilling unmet needs or satisfying needs better (Herzenstein et al. 2007). Therefore, when consumers evaluate a new product, they more or less incorporate these risks and benefits, and their motivational principle to make decisions on new product purchases can be explained by the consumer's regulatory focus.

Crowe and Higgins (1997) showed that promotion-focus is eager to find hits and exhibits risky behavioral bias, whereas prevention-focus is vigilant against mistakes and exhibits conservative behavioral bias. Moreover, individuals with prevention-focus are more likely to exhibit a reluctance to exchange currently possessed objects than individuals with promotion-focus (Liberman et al. 1999). Also, promotion-focused subjects are more flexible to change and pay more attention to revolutionary goods than prevention-focused subjects (Herzenstein et al. 2007). In fact, Herzenstein et al. (2007) showed that promotion-focused individuals have higher purchase intentions of new brands. Therefore, promotion-focused decision-makers tend to readily purchase new products, and prevention-focused decision-makers are reluctant to try them.

Unplanned purchases and new product buying are strongly related as the purchase of a new product is always unplanned for a customer when it is at first sight. Impulsiveness is the characteristic of human beings (Ozen and Engizek, 2014), and it differs from person to person (Dittmar and Drury 2000). Regulatory focus theory implies impulsive buying and new product adoption are closely related. Promotion- 
focused individuals tend to join impulse oriented purchase environment, whereas prevention-focused individuals prefer functional-based activities (Das 2006).

Prevention-focused individuals plan more and carefully consider the product before buying them (Semin et al. 2005) whereas promotion-focused subjects have more impulsive personalities (Friedman and Forster 2002). Thus, promotion-focused individuals tend to engage in unplanned purchases, whereas prevention-focused individuals tend to avoid impulse buying.

2.3 Unplanned / planned trial purchase and repeat purchases

Unplanned purchase causes a change in emotion or mood (Gardner and Rook 1988, Ozer and Gultekin 2015), and the post-purchase emotion or the degree of customer satisfaction is one of the most important factors that determine repeat purchase intention (Anderson and Sullivan 1993; Selnes 1993; Hartline and Jones 1996). Hence, we make predictions based on the emotional aspect of unplanned purchases.

Shoppers make impulse purchases to keep or improve mood (Rook 1987), and their behavior is reflected by the changes in moods and self-feelings (Faber and Christensen 1996). It is also indicated that consumers buy impulsively not only for the economic benefit but also for entertainment or fantasy (Hausman 2000). The trait of impulsiveness is strong for certain customers because planned purchases cannot provide the same excitement (Lee and Yi 2008). As a result, some consumers feel better after engaging in unplanned buying (Rook 1987). In fact, Gardner and Rook (1988) showed impulse-buying shoppers feel satisfied after shopping.

At the same time, several existing studies showed that unplanned buying is related to the feeling of regret and dissonance after purchasing (Hoch and Loewentein 1991; Wood 1998; George and Yaoyuneyong 2010). Consumers regret impulsive purchases made without adequate forethought (Hoch and Loewenstein 1991). George and Yaoyuneyong (2010) stated that unplanned purchase is strongly related to less informed purchases. Without sufficient information, this may result in the wrong product choice, which causes cognitive dissonance (Imam 2013). Lim et al. (2017) also showed that impulsive buying causes post-purchase regret.

Thus, there exist two different results which are obtained from post-purchase 
feelings of unplanned buying. The degree of satisfaction or regret that stems from unplanned buying is strongly associated with the quantity of repurchasing as repeat purchase intention can be a consequence of customer satisfaction and it may be the predictor of subsequent purchasing (Das 2014). Lim et al. (2017) showed that postpurchase emotions are a good predictor of repurchase intention.

Based on these findings, we construct a hypothesis. A promotion-focused individual focuses on more favorable aspects and tends to obtain more positive and happier emotions (Lanaj et al. 2012; Andrews et al. 2014). Moreover, Lin et al. (2018) showed that promotion-focus positively affects customer satisfaction. As it evokes a sensitivity to the presence and absence of positive outcomes, they tend to feel the positive aspects of new product unplanned purchases, such as novelty, entertainment, and fantasy. Moreover, promotion-focused individuals are more likely to repurchase products after enjoying positive emotions (Luoro et al. 2005). Therefore, promotionfocused individuals incur after-purchase satisfaction, leading to higher repurchase intentions. In contrast, as prevention-focus individuals are more sensitive to unfavorable aspects, they accept the negative side of impulsive purchase like regret or dissonance, resulting in a decrease in repurchase intention.

As noted, the unplanned purchasing of new products would be more prominent to promotion-focused individuals than prevention-focused individuals. New product unplanned buying is expected to increase the number of repeat purchases.

H1: Unplanned purchasing of new products positively affects repeat purchases.

2.4 Unplanned new product purchases and category-level loyalty

Brand loyalty is a key driver for repurchasing a product (Dick and Basu 1994; Jacoby and Chestnut 1978). Although our study focuses on new product and as brand loyalty cannot be measured before purchase, the loyalty is also formed at the product category level (Olsen 2002, 2007) because consumers usually classify products into a category and make a purchase decision based on a hierarchical process (Johnson 1989). Moreover, consumer purchase planning often occurs at the category level, rather than at the brand level or stock-keeping unit (SKU) level (Block and Morwitz 1999). 
Lin et al. (2018) showed that loyalty is positively associated with consumer satisfaction and that promotion-focus orientation is positively related to satisfaction as they are more sensitive to the positive aspect of their jobs (Lanaj et al. 2012; Andrews et al. 2014). Therefore, higher loyalty to the category level is associated with a promotionfocus, and they tend to repurchase the product after engaging in new product unplanned purchases. Thus, we posit the following hypothesis:

H2: Those who have higher category loyalty tend to repurchase the new product more after they engage in new product unplanned purchases.

\section{Data and the model}

\subsection{Data}

A unique point of our study is the use of scanner panel data combined with a short questionnaire on unplanned purchases. We can combine these two datasets based on the customer's unique ID code.

The scanner-panel data we used are obtained from MHS (MACROMILL Household Spending Survey) database. MHS is a consumer panel providing information on their every purchase. MHS includes about 20,000 active monitors and is designed to represent the demography. Consumer panelists scan the receipt or the products using a smartphone; then, the product name, the price, and the quantity are recorded based on the image recognition system. Therefore, all the purchases including supermarkets, convenience stores, drug stores, online shopping, vending machines, and so on, are recorded, and this system enables us to identify the first (trial) purchase and the subsequent repeat purchases.

We focus our analysis on 8 beverage brands with one new product that has been placed on the market. The new product is a carbonated beverage and also categorized as "food for specified health uses" (FOSHU). FOSHU refers to foods containing ingredients with better health functions and officially approved to claim positive physiological effects on the human body, as defined by the Ministry of Health, 
Labor, and Welfare in Japan (MHLW). The other 7 beverage products consist of 3 carbonated beverages with FOSHU, 2 carbonated beverages without FOSHU, and 3 green tea beverages with FOSHU. As FOSHU beverages are most prevalent in the green tea category in Japan, 3 green tea brands with FOSHU are included in the analysis. The 7 brands are best-selling products within each category. If consumers of MHS panelists purchased some of the targeted 8 beverages at any channels, they were soon asked to complete a questionnaire on whether the purchase was planned or unplanned as part of the instant research (IR) method through their smartphones.

\subsection{Model}

We model the number of repeat purchases of a new brand considering the effect of trial planned or unplanned purchase using the following zero-inflated Poisson formulation.

$$
\operatorname{Pr}\left(R E P_{i}=j\right)= \begin{cases}\pi_{i}+\left(1-\pi_{i}\right) \exp \left(-\eta_{i}\right) & (j=0) \\ \left(1-\pi_{i}\right) \frac{\eta_{i} \exp \left(-\eta_{i}\right)}{R E P_{i} !} & (j>0)\end{cases}
$$

where

$$
\begin{aligned}
\eta_{i} & =\varphi_{0}+\varphi_{1} U P+\varphi_{2} L O Y_{-} C_{i}+\varphi_{3} L O Y_{-} \operatorname{Sim}_{i}+\varphi_{4} L O Y_{-} B_{i} \\
& +U P_{i} \times\left(\varphi_{5} L O Y C_{i}+\varphi_{6} L O Y_{-} \operatorname{Sim}_{i}+\varphi_{7} L O Y_{-} B_{i}\right) \\
& +\varphi_{8} A G E_{i}+\varphi_{9} M A L E_{i}+\varphi_{10} F A M_{-} S_{Z} I E_{i}+\varphi_{11} I N C_{i}+\varphi_{12} M A I N_{i} \\
& +\lambda_{1} A R E A_{-} F E_{i}+\lambda_{2} J O B_{-} F E_{i}+\lambda_{3} C H A N N E L_{-} F E_{i t}
\end{aligned}
$$

and

$$
\log \left(\frac{\pi_{i}}{1-\pi_{i}}\right)=\tau_{0}+\tau_{1} U P_{i}+\tau_{2} L O Y_{-} C_{i}+\tau_{3} L O Y_{-} S_{i m} C_{i}+\tau_{4} L O Y Y_{-} B_{i} \cdot 1
$$

The definition of variables is provided in Table 1. As some customers no longer buy new products after the trial and the outcome can be zero, we employed zero-inflated specifications. Although we also tried zero-inflated negative binomial regression, the

\footnotetext{
1 For the problem of identifiability, we do not include the cross-term effect and customer demographics.
} 
zero-inflated Poisson regression model had better predictive power. In the regression model predicting repurchase quantity to be zero, we assume logistic regression where variables on unplanned purchase and loyalties are included as predictors.

Table 1 Definition of variables

\begin{tabular}{|c|c|}
\hline Variable name & Definition \\
\hline$R E P i$ & The number of repeat purchases of new brand by shopper $i$. \\
\hline$U P P_{i}$ & Equals to 1 if the purchase is unplanned, and 0 otherwise \\
\hline$L O Y \_C i$ & $\begin{array}{l}\text { Calcualted loyalty to the category to which the new product } \\
\text { belongs (carbonated beverages with FOSHU) of shopper } i \text {. }\end{array}$ \\
\hline LOY_SimC $i$ & $\begin{array}{l}\text { Calcualted loyalty to the similar category to which the new } \\
\text { product belongs (green tea beverages with FOSHU) of shopper } \\
i \text {. }\end{array}$ \\
\hline$L O Y \_B i$ & $\begin{array}{l}\text { Calcualted loyalty to the products of new brand manufacturer of } \\
\text { shopper } i \text {. }\end{array}$ \\
\hline$A G E_{i}$ & Age of the shopper $i$ (year). \\
\hline$M A L E_{i}$ & Equals to 1 if the shopper $i$ is male, and 0 otherwise. \\
\hline FAM_SIZE $i$ & Family size of the shopper $i$ belongs to. \\
\hline$I N C i$ & Natural logarithm of household income the shopper $i$ belongs to. \\
\hline$M A I N i$ & $\begin{array}{l}\text { Equals to } 1 \text { if the shopper } i \text { is the main shopper of the family, } \\
\text { and } 0 \text { otherwise }\end{array}$ \\
\hline AREA_Dummy $i$ & Residence area dummies of the shopper $i$ (10 areas). \\
\hline$J O B \_D u m m y i$ & Job type dummies of the shopper $i$ (13 job types). \\
\hline
\end{tabular}

In addition to a variable indicating unplanned purchase of new product $U P$, we included variables on consumer demography, such as age, gender, family size, income, dummy indicating if they are the main shopper in their family, residence area fixed effect, and job fixed effect.

Customer brand level category $\mathrm{LOY}_{-} \mathrm{C}_{i}$ is measured as follows:

$$
L O Y_{-} C_{i}=\frac{\text { number of purchases of } 3 \text { carbonated beverages with FOSHU by } i}{\text { number of purchases of all tea and carbonated beverages category by } i}
$$

This proxy is calculated based on Bucklin and Lattin (1991). Oliver (1997) and Olsen (2007) also defined loyalty as repeated consumption over time by a unit of a given product category. Therefore, our loyalty metric based on Bucklin and Lattin (1991) is 
consistent with the other studies.

This study also considered two other types of loyalty calculated from consumers' purchase history, the loyalty to the similar category (green tea beverages with FOSHU): $L O Y Y_{-} \operatorname{Sim}_{i}$, and the loyalty to the products of new brand manufacturer: $L O Y_{-} B_{i}$. They are defined as follows:

$$
\begin{gathered}
L O Y_{-} \operatorname{Sim}_{i}=\frac{\text { number of purchases of } 3 \text { green tea beverages with FOSHU by } i}{\text { number of purchases of all tea and carbonated beverages category by } i} \\
L O Y_{-} C_{i}=\frac{\text { number of purchases of } 11 \text { new brand manufacturer products by } i}{\text { number of purchases of all tea and carbonated beverages category by } i}
\end{gathered}
$$

Note that the denominators of three loyalty variables are calculated for all the tea category products and carbonated beverages category products, which are not restricted to the above 8 brands we have used for the analysis.

\section{Results}

\subsection{Descriptive statistics}

Table 2 shows the descriptive statistics of variables. The mean of $U P$ variable is 0.78 , indicating $78 \%$ of the first buying of new products is unplanned purchases. Note that the rest $22 \%$ is planned purchases as the manufacturer had given a large amount of publicity on the new brand before launching.

Table 2 Descriptive statistics of variables

\begin{tabular}{cccccc}
\hline Variable & N & Mean & (S.D.) & p5 & p95 \\
\hline UP & 219 & 0.780 & $(0.415)$ & 0 & 1 \\
LOY_C & 219 & 0.052 & $(0.152)$ & 0 & 0.333 \\
LOY_SimC & 219 & 0.030 & $(0.084)$ & 0 & 0.192 \\
LOY_B & 219 & 0.161 & $(0.192)$ & 0 & 0.520 \\
AGE & 219 & 42.815 & $(8.868)$ & 30 & 57 \\
MALE & 219 & 0.483 & $(0.501)$ & 0 & 1 \\
FAM_SIZE & 219 & 2.498 & $(1.178)$ & 1 & 5 \\
INC & 219 & 6.234 & $(0.562)$ & 4.605 & 7.003 \\
MAIN & 219 & 0.741 & $(0.439)$ & 0 & 1 \\
\hline
\end{tabular}




\subsection{Main results}

Table 3 shows the results from the zero-inflated Poisson regression model, where MODEL 1 considered the case cross term of UP and loyalty variables are not included. The results from MODEL 1 indicate that if the first purchase of a new product is unplanned, succeeding repeat buying tends to increase. The expected quantity of repurchase of a new product for a group with unplanned purchase is $\exp (0.526)=1.69$ times the expected quantity of repurchase for a group with planned buying intention while holding all other variables in the model constant. The result supports hypothesis 1.

If we consider the cross term of $U P$ and loyalty variable (MODEL 2), we find interesting results. The effect of $U P$ becomes moderate compared with MODEL 1 ( 0.526 vs 0.313$)$, the cross term plays a more influential role in the regression model. The estimated coefficients of the cross term between $L O Y{ }_{-} C$ and $U P$ imply that when the shopper has higher loyalty to the category, the unplanned first purchase of a new product considerably increases the succeeding repeat purchases. Hence, hypothesis 2 is also supported. The result $L O Y \_$SimC $\times U P$ indicates that a similar category also forms the category loyalty and becomes a trigger to increase repurchases after new product unplanned buying.

However, the customer who has higher loyalty to the new product manufacturer tends to increase the quantity of repeat buying if the first trial is planned purchase. This might be because those with a higher loyalty to new product manufacturers have already known about the new product launch before market release. Such highly loyal customers engage in new product planned purchase and they continue to repurchase after trial.

The rest of the results obtained from other variables are as follows. If the customer has higher loyalty to the same or similar category of new products, the repurchase quantity would increase. The quantity of repeat purchase of new products would increase by $1-\exp (0.493)=64 \%$ and $1-\exp (0.148)=52 \%$ when the shopper is male and the customer is the main shopper of the family, respectively. The number of repeat purchases of a new product would increase by $1-\exp (0.142)=15 \%$ when family size increases by 1 . 
The logistic regression predicting repurchase quantity to be zero shows similar results to the Poisson regression model predicting repurchase quantity. The probability of a customer engaging in the repurchase of a new product is higher for the unplanned trial purchase case. It is also observed the shoppers, who have a higher loyalty to similar products from the new brand and the product of new brand manufacturers, tend to repeatedly purchase new products.

Table 3 Regression results

\begin{tabular}{|c|c|c|c|c|c|c|c|c|}
\hline \multirow[b]{2}{*}{ Independent Variable } & \multicolumn{4}{|c|}{ MODEL 1} & \multicolumn{4}{|c|}{ MODEL 2} \\
\hline & Estimate & (S.E.) & \multicolumn{2}{|l|}{ t-Value } & Estimate & \multirow[t]{2}{*}{ (S.E.) } & \multicolumn{2}{|l|}{ t-Value } \\
\hline \multicolumn{8}{|c|}{ Poisson regression predicting repurchase quantity } & \\
\hline Intercept & -0.107 & $(1.443)$ & -0.074 & & 0.745 & $(1.504)$ & 0.495 & \\
\hline$U P$ & 0.526 & $(0.193)$ & 2.726 & $* * *$ & 0.313 & $(0.167)$ & 1.873 & $*$ \\
\hline LOY_C & 0.123 & $(0.033)$ & 3.726 & $* * *$ & 0.391 & $(0.143)$ & 2.725 & $* * *$ \\
\hline LOY_SimC & 0.242 & $(0.092)$ & 2.642 & $* *$ & 0.654 & $(0.527)$ & 1.241 & \\
\hline$L O Y \_B$ & -0.146 & $(0.411)$ & -0.355 & & -1.051 & $(0.716)$ & -1.468 & \\
\hline$L O Y \_C \times U P$ & & - & & & 0.578 & $(0.147)$ & 3.923 & $* * *$ \\
\hline$L O Y \_S i m C \times U P$ & & - & & & 0.359 & $(0.230)$ & 1.564 & \\
\hline$L O Y \_B \times U P$ & & - & & & -0.855 & $(0.393)$ & -2.176 & $* *$ \\
\hline$A G E$ & -0.015 & $(0.008)$ & -1.762 & $*$ & -0.013 & $(0.009)$ & -1.477 & \\
\hline$M A L E$ & 0.396 & $(0.249)$ & 1.589 & & 0.493 & $(0.248)$ & 1.987 & $* *$ \\
\hline FAM_SIZE & -0.073 & $(0.079)$ & -0.926 & & 0.142 & $(0.082)$ & 1.728 & $*$ \\
\hline$I N C$ & -0.007 & $(0.152)$ & -0.045 & & -0.017 & $(0.158)$ & -0.106 & \\
\hline MAIN & 0.420 & $(0.215)$ & 1.951 & $*$ & 0.418 & $(0.221)$ & 1.892 & $*$ \\
\hline$A R E A \_F E$ & & Included & & & & Included & & \\
\hline$J O B \_F E$ & & Included & & & & Included & & \\
\hline \multicolumn{9}{|c|}{ Logistic regression predicting repurchase quantity to be zero } \\
\hline Intercept & -0.862 & $(0.538)$ & -1.602 & & -0.811 & $(0.484)$ & -1.675 & \\
\hline$U P$ & -0.763 & $(0.444)$ & -1.720 & $*$ & -0.691 & $(0.390)$ & -1.774 & $*$ \\
\hline LOY_C & -0.353 & $(1.041)$ & -0.339 & & -0.463 & $(1.072)$ & -0.432 & \\
\hline LOY_SimC & -0.322 & $(0.184)$ & -1.753 & $*$ & -0.341 & $(0.193)$ & -1.766 & $*$ \\
\hline$L O Y \_B$ & -0.224 & $(0.125)$ & -1.802 & $*$ & -0.207 & $(0.124)$ & -1.675 & \\
\hline$B I C$ & & 953.281 & & & & 929.340 & & \\
\hline$N$ & & 219 & & & & 219 & & \\
\hline
\end{tabular}

\section{Concluding remarks}

This study investigated the effect of an unplanned purchase of a new product on its succeeding repeat purchase quantity. Following regulatory focus theory, the result using IR showed that if the trial purchase is unplanned, the probability and quantity of new product repurchase tend to increase when compared to planned buying. We also 
found that the impact of unplanned trial purchases is prominent when customers have a higher loyalty to the new product category. Ours is the first study to examine the unplanned buying of new products using real purchase history data.

\subsection{Implications}

This study has several managerial implications. First, the hypothesis revealed that the unplanned purchase of the trial increases repeat purchase. Therefore, shopper marketing strategies like in-store displays, which raises awareness of new products and provides in-store stimuli to customers are extremely helpful to encourage them to purchase again. Contemporary retail stores or shopping malls build recommender systems, and many companies employ mobile ads and coupons, which can be linked to customer location information. This suggests that such in-store promotions causing unplanned new product buying are also useful in recouping the investments made in developing a new brand.

Second, the results also imply that benefits obtained from inducing unplanned purchases of new products would be larger for shoppers who have a higher loyalty to the same or similar category. The loyalty indices used in this study can easily be calculated from customers' purchase history data for retailers who adopt loyalty programs such as frequent shopper programs. As retailers incur the cost of stocking and managing new product introduction, they can recover this cost by stimulating customers with a higher loyalty on the same or similar category, facilitating unplanned purchases and succeeding repeat purchases. In contrast, for shoppers who have more loyalty to the new brand manufacturer, retailers and manufacturers should encourage planned purchases: manufacturers should let their loyal customers recognize the new product before launching it, let them experience a desire to purchase it, and let them purchase it in a planned manner using advertisements or online communications.

Third, the results of the hypothesis built upon regulatory focus theory provide guidelines for managers. As promotion-focused customers react more to positiveoutcome messages, conducting such in-store promotions would persuade customers and induce unplanned buying. Aaker and Lee (2001) conducted experiments where they created a persuasive message for promoting a grape juice product. For promotion- 
focused subjects, the message highlighted positive outcomes such as "energy creating" or "rich in vitamin C and iron" (while "disease-fighting" or "rich in antioxidants" for prevention-focused subjects). They found that such appealing depending on selfregulatory orientation are more persuasive. Hence, the in-store advertising or message appealing benefit obtained from new products would be useful to trigger unplanned purchases for promotion-focused shoppers, leading to long-lasting repeat purchases.

\subsection{Limitations}

We note a potential limitation of our study. Our focus was on a specific beverage category and one new product, and thus, we did not consider the heterogeneity caused by product category differences. As we handled newly introduced products, we considered it mandatory to prepare the research design with a questionnaire about the unplanned purchase before the launch of the new product. However, products where there was a significant time gap between the new release announcement and brought in the market are extremely limited. As such, our study focused on new products that had a sufficient announcements and promotions before they were introduced in the market. Although our hypotheses and prediction might not depend heavily on the category difference, any future research must consider a wider variety of products.

\section{References}

Aaker JL, Lee AY (2001) "I" seek pleasures and "we" avoid pains: The role of selfregulatory goals in information processing and persuasion. Journal of Consumer Research 28:33-49.

Anderson EW, Sullivan MW (1993) The antecedents and consequences of customer satisfaction for firms. Marketing science 12:125-143.

Andrews MC, Kacmar KM, Kacmar C (2014). The mediational effect of regulatory focus on the relationships between mindfulness and job satisfaction and turnover intentions. Career Development International 19:494-507.

Arnold MJ, Reynolds KE (2009) Affect and retail shopping behavior: Understanding the role of mood regulation and regulatory focus. Journal of Retailing, 85:308-320. 
Bell DR, Corsten D, Knox G (2011) From point of purchase to path to purchase: How preshopping factors drive unplanned buying. Journal of Marketing 75:31-45.

Block LG, Morwitz VG (1999) Shopping lists as an external memory aid for grocery shopping: Influences on list writing and list fulfillment. Journal of Consumer Psychology 4:343-375.

Bucklin RE, Lattin JM (1991) A two-state model of purchase incidence and brand choice. Marketing Science 10:24-39.

Chernev A (2004) Goal orientation and consumer preference for the status quo. Journal of Consumer Research 31:557-565.

Crowe E, Higgins ET (1997) Regulatory focus and strategic inclinations: Promotion and prevention in decision-making. Organizational behavior and human decision processes 69:117-132.

Das G (2014) Linkages of retailer awareness, retailer association, retailer perceived quality and retailer loyalty with purchase intention: A study of Indian food retail brands. Journal of Retailing and Consumer Services 21:284-292.

Das G (2016) Regulatory focus as a moderator of retail shopping behaviour. Journal of Strategic Marketing 24:484-499.

Dick AS, Basu, K (1994) Customer loyalty: Toward an integrated conceptual framework. Journal of the Academy of Marketing Science 22:99-113.

Dittmar H, Drury J (2000) Self-image-is it in the bag? A qualitative comparison between “ordinary" and "excessive" consumers. Journal of economic psychology 21:109142.

Faber RJ, Christenson GA (1996) In the mood to buy: Differences in the mood states experienced by compulsive buyers and other consumers. Psychology \& Marketing $13: 803-819$.

Friedman RS, Förster J (2002) The influence of approach and avoidance motor actions on creative cognition. Journal of Experimental Social Psychology 38:41-55.

Gardner MP, Rook DW (1988) Effects of Impulse Purchases on Consumers' Affective States. Advances in consumer research 15:127-130.

George BP, Yaoyuneyong G (2010) Impulse buying and cognitive dissonance: a study conducted among the spring break student shoppers. Young Consumers 11:291-306.

Geroski P, Machin S, van Reenen J (1993) The profitability of innovating firms. The 
RAND Journal of Economics 24:198-211.

Harmancioglu N, Zachary Finney R, Joseph M (2009) Impulse purchases of new products: an empirical analysis. Journal of Product \& Brand Management 18:2737.

Hartline MD, Jones KC (1996) Employee performance cues in a hotel service environment: Influence on perceived service quality, value, and word-of-mouth intentions. Journal of business research 35:207-215.

Hausman A (2000) A multi-method investigation of consumer motivations in impulse buying behavior. Journal of consumer marketing 17:403-426.

Haws KL, Dholakia UM, Bearden WO (2010) An assessment of chronic regulatory focus measures. Journal of Marketing Research 47:967-982.

Herzenstein M, Posavac SS, Brakus JJ (2007) Adoption of new and really new products: The effects of self-regulation systems and risk salience. Journal of Marketing Research 44:251-260.

Higgins ET (1997) Beyond pleasure and pain. American psychologist, 52:1280-1300.

Higgins ET (1998) Promotion and prevention: Regulatory focus as a motivational principle. Advances in experimental social psychology 30:1-46.

Hirschman EC (1980) Innovativeness, novelty seeking, and consumer creativity. Journal of consumer research, 7:283-295.

Hoch SJ, Loewenstein GF (1991) Time-inconsistent preferences and consumer selfcontrol. Journal of consumer research 17:492-507.

Hui SK, Huang Y, Suher J, Inman JJ (2013). Deconstructing the "first moment of truth": Understanding unplanned consideration and purchase conversion using in-store video tracking. Journal of Marketing Research 50:445-462.

Imam F (2013) Gender differences in impulsive buying behavior and post-purchasing dissonance under incentive conditions. Journal of Business Strategy 7:23-29.

Inman JJ, Winer RS, Ferraro R (2009) The interplay among category characteristics, customer characteristics, and customer activities on in-store decision making. Journal of Marketing 75:19-29.

Jacoby J, Chestnut RW (1978) Brand loyalty measurement and management. New York: Wiley.

Johnson MD (1989) The differential processing of product category and noncomparable 
choice alternatives. Journal of Consumer Research 16:300-309.

Jung HS, Yoon HH (2015) Understanding regulatory focuses. International Journal of Contemporary Hospitality Management 27:283-307.

Krishnan TV, Jain DC (2006) Optimal dynamic advertising policy for new products. Management Science 52:1957-1969.

Lanaj K, Chang CH, Johnson RE (2012) Regulatory focus and work-related outcomes: a review and meta-analysis. Psychological bulletin, 138:998-1034.

Lee GY, Yi Y. (2008) The effect of shopping emotions and perceived risk on impulsive buying: the moderating role of buying impulsiveness trait. Seoul Journal of Business 14:67-92.

Liberman N, Idson LC, Camacho CJ, Higgins ET (1999) Promotion and prevention choices between stability and change. Journal of personality and social psychology $77: 1135-1145$.

Lim SH, Lee S, Kim DJ (2017) Is online consumers' impulsive buying beneficial for ecommerce companies? An empirical investigation of online consumers' past impulsive buying behaviors. Information Systems Management 34:85-100.

Lin CT, Chen CW, Wang SJ, Lin, CC (2018) The influence of impulse buying toward consumer loyalty in online shopping: a regulatory focus theory perspective. Journal of Ambient Intelligence and Humanized Computing, 1-11. https://doi.org/10.1007/ s12652-018-0935-8.

Louro MJ, Pieters R, Zeelenberg M (2005) Negative return on positive emotions: the influence of pride and self-regulatory goals on repurchase decisions. Journal of Consumer Research 31:833-40

Olsen SO (2002) Comparative evaluation and the relationship between quality, satisfaction, and repurchase loyalty. Journal of the Academy of Marketing Science 30:240-249.

Olsen SO (2007) Repurchase loyalty: the role of involvement and satisfaction. Psychology and Marketing 24:315-341.

Olshavsky RW, Spreng RA (1996) An exploratory study of the innovation evaluation process. Journal of product innovation management 13:512-529.

Ozen H, Engizek N (2014) Shopping online without thinking: being emotional or rational? Asia pacific journal of marketing and logistics 26:78-93. 
Ram S, Sheth JN (1989) Consumer resistance to innovations: The marketing problem and its solutions. The Journal of Consumer Marketing 6:5-14.

Rook DW (1987) The buying impulse. Journal of Consumer Research14:189-99.

Rogers EM (1995) Diffusion of innovations. New York, 12.

Saleh MAH (2012) An investigation of the relationship between unplanned buying and post-purchase regret. International Journal of Marketing Studies 4:106-120.

Selnes F (1993) An examination of the effect of product performance on brand reputation, satisfaction and loyalty. European Journal of marketing 27:19-35.

Semin GR, Higgins T, de Montes LG, Estourget Y, Valencia JF (2005) Linguistic signatures of regulatory focus: how abstraction fits promotion more than prevention. Journal of personality and social psychology 89: 36-45.

Stern H (1962) The significance of impulse buying today. Journal of Marketing 26:59-62.

Wind J, Mahajan V (1997) Issues and opportunities in new product development: An introduction to the special issue. Journal of Marketing Research 34:1-12.

Wood M. (1998) Socio-economic status, delay of gratification, and impulse buying. Journal of economic psychology 19:295-320.

Yeo J, Park J (2006) Effects of parent-extension similarity and self regulatory focus on evaluations of brand extensions. Journal of consumer psychology 16:272-282. 